\title{
The Use of Orthotic Insoles to Prevent Lower Limb Overuse Injuries: A Critically Appraised Topic
}

\author{
Janie L. Kelly and Alison R. Valier
}

\begin{abstract}
Overuse injuries are common in physically active populations. Lower limb overuse injuries can occur anywhere in the lowerextremity and include injuries such as medial tibial stress syndrome, plantar fasciitis, and anterior knee pain. One reason that overuse injuries have received attention is because they have both short- and long-term consequences on health and burden the lives of physically active people. Over the years, a variety of approaches have been proposed for prevention of lower limb overuse injury that addresses various intrinsic or extrinsic risk factors. One extrinsic risk factor is footwear and the use of orthotic insoles to prevent injury. To date, there is no consensus as to whether these supports prevented lower limb overuse injuries. A critical appraisal of recent studies examining the injury prevention capabilities of orthotic insoles was completed. The long-term objective of this research is to help identify effective strategies for preventing injuries in physically active people.
\end{abstract}

Keywords: athletic training, prevention, injury management, chronic

\section{Clinical Scenario}

Overuse injuries are common in physically active populations. A recent report regarding college athletes concluded that overuse injuries occur at a rate of 5.36 per 10,000 athlete-exposures. ${ }^{1}$ Reports on military ${ }^{2}$ and running ${ }^{3}$ populations have suggested that overuse injuries make up anywhere from $20 \%$ to $65 \%$ of injuries. Furthermore, approximately $70 \%$ of overuse injuries in high school and college athletes occurred in the lower-extremity. ${ }^{1}$

Lower limb overuse injuries (LLOIs) can occur anywhere in the lower-extremity, spanning from the feet to the thighs. ${ }^{2}$ Medial tibial stress syndrome, general overuse or stress syndromes, stress fractures, patellofemoral pain, tendinopathies, and plantar fasciitis are examples of common LLOIs. ${ }^{2,4}$ Risk factors for LLOIs can be either intrinsic or extrinsic. Intrinsic risk factors include age, skill level, and biomechanics, whereas extrinsic factors include footwear and equipment, activity level, and playing surface. ${ }^{1,2,5,6}$ Although there is no single cause of LLOIs, attention has been given to the impact of repetitive stress or rapid increases in training or load as sources of these injuries. ${ }^{2,4}$ One reason that overuse injuries have received attention is because they have both short- and long-term consequences on health. For example, not only can LLOIs result in significant pain and lost training and playing time when the injury occurs, but they can also impact a person's mental and physical health and lead to musculoskeletal disorders later in life. ${ }^{1,7,8}$

Given the burden of LLOIs among physically active adults, it is important to identify an injury prevention strategy for this important population. Over the years, a variety of approaches have been proposed for prevention of LLOI that address various intrinsic or extrinsic risk factors. One extrinsic risk factor that received much attention in the 80s and 90s was footwear and the use of arch supports or orthotic insoles. Although several studies

The authors are with Athletic Training Programs, Department of Interdisciplinary Health Sciences, A.T. Still University, Mesa, AZ. Valier is also with the School of Osteopathic Medicine in Arizona, A.T. Still University, Mesa, AZ; and the Department of Research Support, A.T. Still University, Mesa, AZ. Valier (arsnyder@atsu.edu) is corresponding author. investigated orthotic insoles, no consensus was produced as to whether these supports prevented LLOIs. ${ }^{9}$ Since those studies, there have been advances in technology and manufacturing of footwear and orthotic insoles and more related research has been produced, which makes it possible that the available evidence more clearly answers the question as to whether orthotic insoles can prevent LLOIs in physically active adults.

\section{Clinical Question}

In physically active adults, does wearing orthotic insoles prevent LLOIs when compared with not wearing insoles?

\section{Summary of Search, "Best Evidence" Appraised, and Key Findings}

- The search targeted level 3 studies or greater that investigated the use of orthotic insoles or shock-absorbing insoles (SAIs) to prevent LLOIs.

- Two randomized controlled trials ${ }^{7,10}$ and 1 cohort study ${ }^{11}$ were critically appraised for our clinical question.

- All 3 studies used different insoles, which included customized D3D orthotics, ${ }^{7}$ thermal-molded orthotics, ${ }^{10}$ and SAIs. ${ }^{11}$

- Two studies ${ }^{7,11}$ reported a lower incidence of LLOI with use of orthotic insole but 1 study ${ }^{10}$ did not.

- The 2 types of orthotics that demonstrated injury prevention potential were the customized D3D orthotic ${ }^{7}$ and the SAI. ${ }^{11}$

\section{Clinical Bottom Line}

Evidence was found to address the clinical question regarding whether wearing orthotic insoles will prevent LLOIs in physically active adults. All included studies targeted large military populations and compared the military standard issue insole with an orthotic insole. Commonly reported LLOIs included achilles tendinopathy, ${ }^{7,10,11}$ anterior knee pain,, ${ }^{7,10,11}$ medial tibial stress 
syndrome, ${ }^{7,10,11}$ stress fractures, ${ }^{7,11}$ plantar fasciitis, ${ }^{7,11}$ and blisters. ${ }^{10,11}$ Unspecified LLOI injuries were also reported. ${ }^{10,11}$ Because of the inconsistent findings, it is not possible to state with absolute confidence that wearing orthotic insoles will prevent LLOIs. Given that 2 recent studies concluded that wearing orthotic insoles reduced the incidence of injury, evidence does exist to support their use. More research is needed to further explore differences between available orthotic insoles to make a more definitive conclusion regarding the injury prevention benefits of orthotic insoles. Clinicians should continue to seek injury prevention strategies supported by available evidence and consider orthotic insoles as a potential strategy.

\section{Strength of the Recommendation}

Grade B evidence is available to determine whether insoles are effective at preventing LLOIs.

\section{Search Strategy}

\section{Terms Used to Guide Search Strategy}

1. Patient/Client Group: Physically active adults

2. Intervention: Orthotics OR orthoses OR insoles

3. Comparison: No insole

4. Outcome: Lower limb overuse injury OR LLOI OR lower limb injury

\section{Sources of Evidence Searched}

1. Library discovery tools that included multiple databases

- MEDLINE complete

- SPORTDiscus

- CINAHL Plus

- ScienceDirect

- Business Source Premier

- PsycINFO

- Education Abstracts (H.W. Wilson)

- Cochrane Database of Systematic Reviews

- ERIC

2. Separate searches within single databases

- Cochrane Library

- PubMed

- Google

- Google Scholar

3. Additional studies explored through related article searches and hand searching of reference lists

\section{Inclusion and Exclusion Criteria}

\section{Inclusion}

1. Studies that investigated the use of orthotics, insoles, or SAIs to prevent LLOIs.

2. Studies that included physically active adults, defined by being a participant in (1) individual or team athletics or sports, (2) high-intensity physical training, or (3) high-level physical performance.
3. Studies that included adults, $\geq 18$ years old.

4. Studies that included evaluating the incidence of LLOIs.

5. Limited to studies reported in English.

6. Limited to studies of level 3 evidence or better.

7. Limited to the last 10 years (2006-2015).

\section{Exclusion}

1. Studies that did not investigate injury prevention, such as injury management.

2. Studies that investigated non-LLOI, such as back injuries or upper limb injuries.

3. Studies that investigated acute lower limb injuries, such as an anterior cruciate ligament tear.

\section{Results of Search}

Following the search strategy, 3 studies met the inclusion and exclusion criteria. All studies are presented in Table 1.

\section{Best Evidence}

The search strategy resulted in identifying a total of 3 studies (Table 2) that are considered to be the best evidence available to help answer the question. Studies were selected based on the classification of level of evidence 3 or better, focus on the use of orthotics, insoles, or SAIs to prevent LLOIs, and inclusion of a physically active adult population.

\section{Implications for Practice, Education, and Future Research}

The 3 studies ${ }^{7,10,11}$ included in this critically appraised topic (CAT) evaluated the use of orthotic insoles to prevent LLOIs in physically active adult populations by comparing the incidence of injury between people who did and did not use an orthotic insole. Two $^{7,11}$ of the studies reported a decreased incidence of injury in physically active people who wore an orthotic insole and supported the use of orthotic insoles to prevent LLOIs in the physically active population. The difference in the percentage of people who were injured while wearing and not wearing orthotic insoles was as great as $20 \% .^{7}$ One study ${ }^{10}$ differed from the others and concluded that the incidence of injury between physically active people who did and did not wear orthotic insoles was similar. Thus, these authors concluded that orthotic insoles were not an effective injury prevention strategy. Taken together, there is inconsistent evidence that addresses our question, but the majority of the

\section{Table 1 Summary of Study Designs of Retrieved} Articles

\begin{tabular}{llcl}
\hline $\begin{array}{l}\text { Level of } \\
\text { evidence }\end{array}$ & $\begin{array}{l}\text { Study } \\
\text { design }\end{array}$ & $\begin{array}{l}\text { Number } \\
\text { located }\end{array}$ & Author \\
\hline 2 & RCT & 2 & $\begin{array}{l}\text { Franklyn-Miller et al } \\
\text { Mattila et al }\end{array}$ \\
3 & Cohort & 1 & $\begin{array}{l}\text { House et al } \\
\text { H1 }\end{array}$ \\
\hline
\end{tabular}

Abbreviation: RCT, randomized controlled trial. 
Table 2 Characteristics of Included Studies

\begin{tabular}{|c|c|c|c|}
\hline Characteristic & Franklyn-Miller et al $^{7}$ & Mattila et al ${ }^{10}$ & House et al ${ }^{11}$ \\
\hline Study design & RCT & RCT & Cohort \\
\hline Participants & $\begin{array}{l}400 \text { male and female new entry } \\
\text { officer cadets with a medium to high } \\
\text { risk of injury, based on plantar } \\
\text { pressure patterns, were randomly } \\
\text { assigned to either orthotic group } \\
\text { ( } \mathrm{n}=200 ; 124 \text { males and } 76 \text { females) } \\
\text { or control group }(\mathrm{n}=200 ; 136 \text { males } \\
\text { and } 64 \text { females). } \\
\text { Cadets were excluded based on } \\
\text { preexisting orthotic use, recent }\end{array}$ & $\begin{array}{l}220 \text { male military conscripts were } \\
\text { randomly assigned to an orthotic } \\
\text { group }(n=73) \text { or control group } \\
(n=147) \text {. } \\
\text { Conscripts were excluded based on } \\
\text { preexisting use of insoles or existing } \\
\text { orthopedic or medical condition. }\end{array}$ & $\begin{array}{l}2774 \text { military recruits were included } \\
\text { in study and were assigned to the } \\
\text { Saran insole control group } \\
\text { ( } \mathrm{n}=1416) \text { or SAI experimental } \\
\text { group }(\mathrm{n}=1358) \text { based on phase of } \\
\text { entry into the study (ie, phase } 1 \text { or } \\
\text { 2). Both phase } 1 \text { and } 2 \text { started at the } \\
\text { beginning of training. } \\
\text { Recruits were excluded if they wore } \\
\text { custom-made orthotics. }\end{array}$ \\
\hline
\end{tabular}

Intervention investigated Primary outcome
measure

Main finding

$\begin{array}{ll}\text { PEDro score } & 6 \\ \text { Level of evidence } & 2 \\ \text { Conclusion } & \begin{array}{l}\text { The use of prescription orthotics } \\ \text { reduced the risk of LLOI in male } \\ \text { and female officer cadets. }\end{array}\end{array}$

Lower limb overuse injury (eg, achilles tendinopathy, anterior knee pain, medial tibial stress syndrome) reported by the participant, diagnosed by a nurse, and confirmed by a physician. Injuries must have resulted in the removal of the recruit from at least $2 \mathrm{~d}$ of training.

\section{LLOI injuries were sustained} $(n=21$ in orthotic group and $n=61$ in the control group). The injury rate in the orthotic group was 1 injury per $4666 \mathrm{~h}$ and in the control group was 1 injury per $1600 \mathrm{~h}$ of training. A strong association between orthotics use and injury risk reduction existed $\left(\chi^{2}=34.39, P<.001\right)$. Orthotics resulted in an absolute risk reduction of $0.49(P<.001$ chi-squared; CI, 1.7-2.4). Overall, 2 people would need to be treated to prevent 1 LLOI.
All participants were given standard issue boots. Under nurse supervision, the orthotic group had insoles thermally molded to their feet and were instructed to use them in their boots. The control group was instructed to wear boots.

All participants were subject to the same training program that consisted of an initial 8-wk training program followed by another 4 mo of service at about the same intensity rate.

Lower limb overuse injury, documented as specified or unspecified, reported by the participants and evaluated by a physician who was blinded to treatment groups. Only injuries that required suspension from duty were included.

The orthotic group sustained a similar number of LLOI $(n=34$; $46.6 \%)$ to the control group $(\mathrm{n}=56$; $38.1 \%), P=.29$.

Mean suspension duration for the orthotic group and the control group was 2.4 (2.0) d and 1.8 (2.0) d, respectively.

The hazard ratio for LLOIs in the orthotic group compared with the control group was 1.3 (95\% CI, 0.8$0.21)$.

\section{9}

2

Molded insoles, or orthotics, are not an effective prevention strategy for LLOI in people with typical feet.
In the first phase, recruits were issued standard military boots with Saran insole (control group). In the second phase, recruits were issued the same standard military boot but with SAI (orthotic group).

All recruits completed the same 32wk training protocol.

Lower limb overuse injury diagnosis (eg, stress fracture, anterior knee pain, achilles tendinopathy, plantar fasciitis, blister) that was documented in the participants medical file. Two medical professionals confirmed all included injuries.

The SAI group sustained fewer LLOIs than the control group whether accounting for (ie, removing) blister injuries (SAI: $\mathrm{n}=258 ; 19.0 \%$; control: $\mathrm{n}=446 ; 31.7 \%), P<.001$; or not (SAI: $\mathrm{n}=453 ; 33.4 \%$; control: $\mathrm{n}=589 ; 41.9 \%), P<.001$.

The odds of sustaining a LLOI was 1.96 (95\% CI, 1.22-1.66) when accounting for blister injuries and 1.42 (95\% CI, 1.64-2.34) when considering all injuries.

Overall, 12 people would need to wear the SAI insoles to prevent a LLOI when including blisters as an injury and 8 would need to wear the SAI insoles to prevent a LLOI when not including blisters as an injury. NA 3

Wearing SAIs reduced the incidence of LLOI in military recruits.

Abbreviations: CI, confidence interval; LLOI, lower limb overuse injury; NA, not applicable; RCT, randomized controlled trial; SAI, shock-absorbing insole. 
evidence suggests that wearing orthotic insoles helps in the prevention of LLOIs.

When considering all of the studies, there are particular characteristics that should be evaluated and compared in order to determine if the inconsistent findings may be due to differences in aspects of the study, such as length of follow-up, definition of injury, or types of orthotic insoles studied. All of the included studies incorporated large populations of military recruits $(n>200)$ and tracked them anywhere from 7 weeks to 8 months. The shortest ${ }^{7}$ and longest ${ }^{11}$ duration of study follow-up resulted in data in support of the use of orthotic insoles; thus, a reason for the difference in finding is likely not due to the length of injury tracking.

Another important characteristic to consider when evaluating the evidence for our clinical question is the definition of injury because it identifies the types of injuries that were counted in each study. All of the studies required the injuries to be in the lowerextremity, overuse in nature, and reviewed by a medical personnel. Two of the studies ${ }^{7,11}$ listed specific diagnoses to be counted as an LLOI and included such injuries as anterior knee pain, stress fractures, patellar tendinopathy, iliotibial band syndrome, medial tibial stress syndrome, and plantar fasciitis. Two studies ${ }^{10,11}$ made reference to the inclusion of blisters in their consideration of LLOI but 1 study did not. ${ }^{7}$ Blisters may result from the introduction of the new insoles to the foot; thus, classifying blisters as an overuse injury may be debatable. No differences were noted in the incidence of blisters in the orthotic insole or control group in either study. Thus, it is unlikely that the inclusion of blisters impacted the results of this CAT. Overall, it appears that the included studies used a similar definition of injury; thus, differences in study results are likely not due to the injury definition.

Finally, when comparing the studies, review of the specific orthotic insoles used by participants is important. Many different orthotic insoles are discussed in the literature, and the variety of insole options was apparent in the 3 studies that met our inclusion criteria. All of the included studies used a different type of orthotic insole, 2 of which showed promise in preventing injuries. ${ }^{7,11}$ The insole used by Franklyn-Miller et $\mathrm{al}^{7}$ was a modular injectionmolded insole, referred to as the $\mathrm{D} 3 \mathrm{D}$, which comes in varying densities and support levels. Based on force plate testing, the D3D insole was customized in 4 areas of the foot, making it highly specific to the person wearing it and may be a reason for the injury prevention benefit. ${ }^{7}$ The other insole that demonstrated injury prevention characteristics was a SAI that was constructed out of several layers of polyurethane foam, with a felt overlay, that was not specifically formatted to fit the individual. ${ }^{11}$ The remaining insole did not lead to injury prevention. This insole, the Thermo +Camel, was made with a firm-density polyethylene material and a hard plastic shell. ${ }^{10}$ Of importance is that the Thermo+Camel insole was form fitted to the individual's feet, much like the D3D. However, the D3D insole decreased the incidence of injury but Thermo+Camel did not. It is possible that the materials used to construct the Thermo+Camel insole were not as forgiving or able to absorb forces as well as the other 2 insoles. Given the results of the 3 studies, more research into the styles of insoles is needed.

One of the biggest factors when using any type of intervention strategy is cost. Cost of insoles can vary from fairly inexpensive to very expensive. Ability to purchase the orthotic insole may drive the selection because some insoles may be cost prohibitive. Unfortunately, information regarding costs of the insoles was not provided in all studies reviewed. From what we know, the custom-made and fitted D3D insole that was constructed from biomechanic characteristics of the foot costs about $\$ 73 .{ }^{7}$ Cost of the other 2 insoles was not disclosed. SAIs like the one used by House et $\mathrm{al}^{11}$ can be purchased easily from local pharmaceutical stores, which is likely cheaper than custom-made insoles. Given the inconclusiveness of the findings, trying a cheaper, more accessible insole may be an acceptable starting point for injury prevention.

Cost can also be considered from a cost-saving perspective when evaluating the size of impact of the intervention on an outcome. A closer look at the cost savings presented by House et $\mathrm{al}^{11}$ provides an illustration of the benefit that a small intervention, like orthotic insoles, can have on health care costs. According to House et al, ${ }^{11}$ the cost per military recruit for rehabilitating an injury is over $\$ 1000$ a week. When analyzing the reduction of only stress fracture and periostitis LLOI, they estimated that the orthotic insoles would save millions of dollars annually. Clearly, the savings would be even higher if other LLOIs were included. Performance of cost-benefit analysis of the use of orthotic insoles to prevent injuries is needed in other physically active populations.

Although the 3 studies reviewed in this CAT provided useful information to further the understanding of the use of orthotics to prevent injuries, they are not without limitations. The primary limitations were the population studied and the unique activity that these individuals were involved in. Each study examined the use of orthotic insoles in entry-level military recruits who participated in a standardized training regimen that required wearing military boots. Although the military population fits our inclusion criteria, the type of activity these trainees experienced is likely greater than that experienced by the average physically active person. For example, the use of military boots to complete physical activities is not common. Furthermore, it is unclear whether the rapid increase in training level that the military recruits experienced is similar to the ramp up of intensity that typical athletes experience, such as when entering a new sports season. Although these 3 studies give us insight into the impact of orthotic insoles on the injury risk of physically active people, more research is needed in different types of physically active populations, such as competitive and recreational athletes.

Ultimately, the information available within the last 10 years is inconsistent and targets a narrow physically active population. In the future, more high-quality research studies are needed to determine the effectiveness of orthotic insoles as a prevention strategy for LLOIs in all physically active populations. Given advances in technology, specific attention should be placed on the type of insoles used. This CAT should be reviewed in 2 years and updated if there are newer, high-quality studies available to better answer the clinical question.

\section{References}

1. Roos KG, Marshall SW, Kerr ZY, et al. Epidemiology of overuse injuries in collegiate and high school athletics in the United States. Am J Sports Med. 2015;43(7):1790-1797. PubMed ID: 25930673 doi:10. $1177 / 0363546515580790$

2. Kaufman KR, Brodine S, Shaffer R. Military training-related injuries. Surveillance, research, and prevention. Am J Prev Med. 2000;18(suppl 1):54-63. doi:10.1016/S0749-3797(00)00114-8

3. Taunton JE, Ryan MB, Clement DB, McKenzie DC, Lloyd-Smith DR, Zumbo BD. A prospective study of running injuries: the Vancouver Sun Run "In Training" clinics. Br J Sports Med. 2003; 37(3):239-244. PubMed ID: 12782549 doi:10.1136/bjsm.37.3.239

4. Baxter ML, Ribeiro DC, Milosavljevic S. Do orthotics work as an injury prevention strategy for the military? Phys Ther Rev. 2012;17(4):241-251. doi:10.1179/1743288X12Y.0000000013 
5. Jenkins S. Applied anatomy and biomechanics in sport, 2nd Edition. Int J Sports Science Coaching. 2009;4(2):293-297. doi:10.1260/ 174795409788549535

6. Murphy DF, Connolly DAJ, Beynnon BD. Risk factors for lower extremity injury: a review of the literature. Br J Sports Med. 2003; 37(1):13-29. doi:10.1136/bjsm.37.1.13

7. Franklyn-Miller A, Wilson C, Bilzon J, McCrory P. Foot orthoses in the prevention of injury in initial military training. Am J Sports Med. 2011;39(1):30-37. PubMed ID: 21041512 doi:10.1177/ 0363546510382852

8. Hootman JM, Dick R, Agel J. Epidemiology of collegiate injuries for 15 sports: summary and recommendations for injury prevention initiatives. J Athl Train. 2007;42(2):311-319. PubMed ID: 17710181
9. Vicenzino B. Foot orthotics in the treatment of lower limb conditions: a musculoskeletal physiotherapy perspective. Man Ther. 2004; 9(4):185-196. PubMed ID: 15522643 doi:10.1016/j.math.2004. 08.003.

10. Mattila VM, Sillanpää PJ, Salo T, Laine HJ, Mäenpää H, Pihlajamäki H. Can orthotic insoles prevent lower limb overuse injuries? A randomized-controlled trial of 228 subjects. Scan J Med Sci Sports. 2011;21(6):804-808. doi:10.1111/j.1600-0838.2010.01116.x

11. House C, Reece A, Roiz de Sa D. Shock-absorbing insoles reduce the incidence of lower limb overuse injuries sustained during royal marine training. Mil Med. 2013;178(6):683-689. PubMed ID: 23756077 doi:10.7205/MILMED-D-12-00361 